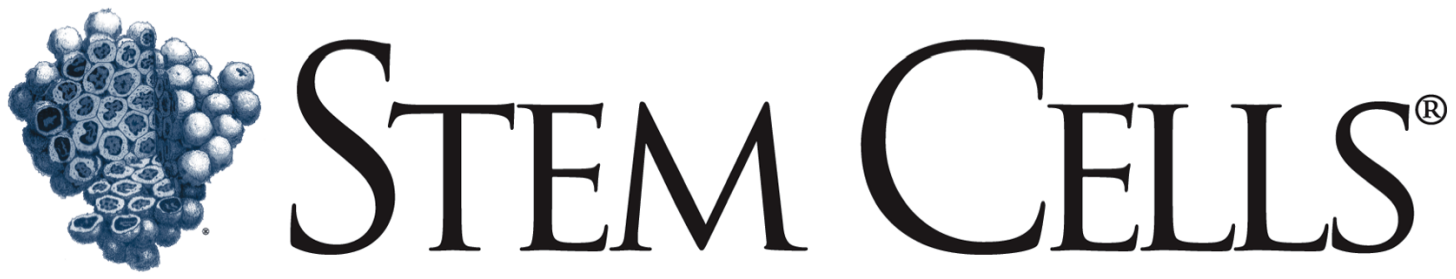

Transcriptional Control of T Lymphocyte Differentiation

Frank J.T. Staal, Floor Weerkamp, Anton W. Langerak, Rudi W. Hendriks and Hans C. Clevers

Stem Cells 2001;19;165-179

DOI: $10.1634 /$ stemcells.19-3-165

This information is current as of November 27, 2006

The online version of this article, along with updated information and services, is located on the World Wide Web at:

http://www.StemCells.com/cgi/content/full/19/3/165

STEM CELLS $®$, an international peer-reviewed journal, covers all aspects of stem cell research: embryonic stem cells; tissue-specific stem cells; cancer stem cells; the stem cell niche; stem cell genetics and genomics; translational and clinical research; technology development.

STEM CELLS $®$ is a monthly publication, it has been published continuously since 1983 . The Journal is owned, published, and trademarked by AlphaMed Press, 318 Blackwell Street, Suite 260, Durham, North Carolina, 27701. (C) 2001 by AlphaMed Press, all rights reserved. Print ISSN: 1066-5099. Online ISSN: 1549-4918.
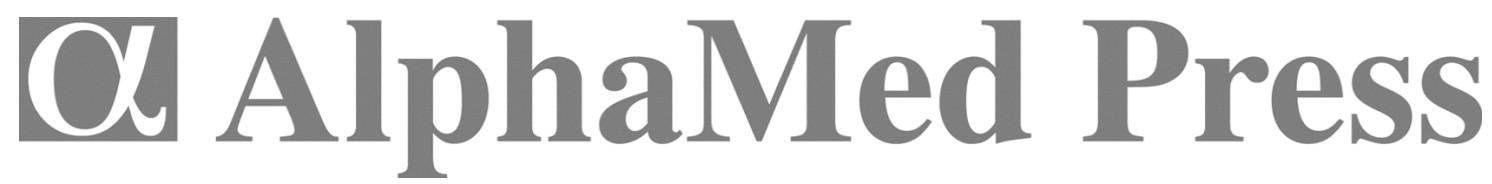


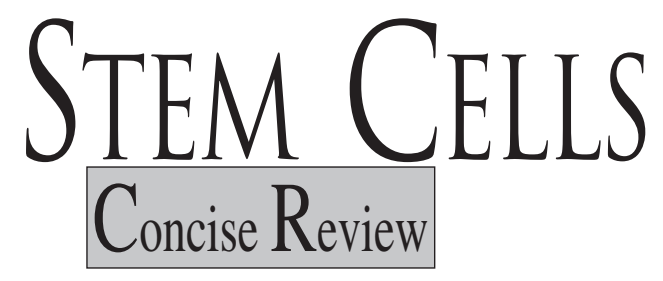

\title{
Transcriptional Control of T Lymphocyte Differentiation
}

\author{
Frank J.T. StaAl, ${ }^{\mathrm{a}}$ Floor WeErkamp, ${ }^{\mathrm{a}}$ Anton W. Langerak, ${ }^{\mathrm{a}}$ \\ Rudi W. Hendriks, ${ }^{a}$ Hans C. Clevers ${ }^{b}$ \\ aDepartment of Immunology, Erasmus University Rotterdam, Rotterdam, Netherlands; \\ ${ }^{b}$ Department of Immunology, Utrecht University Medical Center, Utrecht, Netherlands
}

Key Words. Transcription factor $\cdot$ Thymus $\cdot T$ cell $\cdot$ Development $\cdot$ Signal transduction

\begin{abstract}
Initiation of gene transcription by transcription factors (TFs) is an important regulatory step in many developmental processes. The differentiation of $\mathbf{T}$ cell progenitors in the thymus is tightly controlled by signaling molecules, ultimately activating nuclear TFs that regulate the expression of $\mathbf{T}$ lineage-specific genes. During the last 2 years, significant progress has been made in our
\end{abstract}

understanding of the signaling routes and TFs operating during the earliest stages of thymic differentiation at the CD4-CD8- double negative stage. Here we will review the TF families that play an important role in differentiation of thymocytes, particularly focusing on recent new information with respect to the Tcf, bHLH, GATA, and CBF/HES TF families. Stem Cells 2001;19:165-179

\section{INTRODUCTION}

Regulation of gene expression, establishing cell- or differentiation stage-specific gene expression profiles, occurs at multiple levels. These include opening of a locus for the transcriptional machinery, initiation of RNA transcription by transcription factors (TFs) that attract the RNA polymerase II complex, RNA splicing, transport of transcripts out of the nucleus, mRNA stability, and in a broad sense, translation and post-translational modifications of the gene products (proteins) such as (de)phosphorylation and glycosylation [1]. Initiation of transcription is probably the most important regulatory step in control of gene expression. TFs, proteins that bind to specific DNA sequences present in the core promoters and enhancers of genes, are important in the initiation of gene-specific transcription. Before they can exert their action, initiation of transcription is controlled by more global mechanisms that regulate accessibility of a locus. This level of regulation is mediated by changes in chromatin structure through changes in histone acetylation of nucleosomal DNA and demethylation of CpG dinucleotides. In addition to decondensation of chromatin, silencers and locus control regions regulate global changes in gene expression [1].

Recent evidence has shown that this strict separation between specific TFs and factors that regulate locus accessibility is an oversimplified model. Certain TFs also attract factors that mediate (de)acetylation of histones thereby regulating chromatin remodeling [2-5].

Most of the TFs we now know to be important for $\mathrm{T}$ cell differentiation were identified by promoter/enhancer studies of T cell-specific genes, such as the CD3 and T cell receptor (TCR) genes. Others were originally found in B cells, but turned out to play pivotal roles in T cell development as well. Since TFs do not function in isolation, much

Correspondence: Frank J.T. Staal, Ph.D., Department of Immunology, Erasmus University Rotterdam, Dr. Molewaterplein 50, 3015 GE Rotterdam, The Netherlands. Telephone: 31-104088089; Fax: 31-104089456; e-mail: f.j.t.staal@immu.fgg.eur.nl Received February 1, 2001; accepted for publication February 2, 2001. @AlphaMed Press 1066-5099/2001/\$5.00/0 
attention has recently been devoted to the interaction with other proteins and the signaling routes controlling TFs during development. For instance, we now know about the importance of the balance in expression levels of E2A TFs and their dominant-negative interacting partners, the Ids. We have learned that Tcf/Lef TFs are the downstream effectors of the evolutionary conserved Wnt pathway. Studies of the Notch pathway, a signaling pathway critically important at many stages of $\mathrm{T}$ cell differentiation, have revealed a whole new class of TFs, the CBF and HES families, that are likely to be important for T cell development. We will systematically discuss these different factors here focusing on more recent discoveries, after we have given a short overview of the different stages of $\mathrm{T}$ cell differentiation in the thymus. For extensive descriptions of the discovery of these TFs, expression pattern and phenotype of the nullmutant mice that were generated, the reader is referred to any of the many reviews that were published recently [6-10].

\section{Stages of T Cell Differentiation}

T cells develop from common lymphoid progenitor cells that seed the thymus from the fetal liver or bone marrow [11]. $\mathrm{T}$ cells differentiating in the thymus are phenotypically distinguished by the expression of CD4 and CD8 co-receptors; T cells are either double negative (DN), double positive (DP), or single positive (SP) for these two cell-surface antigens (Fig. 1). During the DN stage T cells can be subdivided into four distinct subsets (DN1-4), based on rearrangement of their TCR genes and the expression of surface antigens. In the mouse these antigens are CD44 and CD25 in the following order: $\mathrm{CD} 44^{+} \mathrm{CD} 25^{-}$(DN1), CD44+CD25+ (DN2), CD44-CD25+ (DN3), and CD44-CD25- (DN4).

T cells rearrange their TCRD locus in the DN1 stage and the $T C R G$ locus in the DN2 stage [12]. During the transition to the next stage of $\mathrm{T}$ cell maturation, the pre- $\mathrm{T}$ cell stage (DN3), the cells shut down proliferation [13] and TCR $\beta$ genes begin to rearrange. During the immature single positive (ISP) stage the rearranged TCR $\beta$ is expressed at the cell surface complexed to pre-T $\alpha$ as the pre-TCR-complex. In the mouse these ISP cells express CD8, while in humans they express CD4. In both species, the ISP cells represent a stage of rapid proliferation, driven by signals emanating from pre-TCR. The resultant DP cells comprise 85\%-90\% of an adult thymus and, after rearranging their TCRA locus, undergo positive (for recognition of self-major histocompatibility) and negative (against autoreactivity) selection. DP cells which fail to receive the TCR-mediated signal within 3-4 days will enter the apoptotic pathway, while selected cells develop into CD4 or CD8 SP cells that have high CD3/TCR expression. These cells exit the thymus and become circulating $\mathrm{T}$ cells that reside in blood and peripheral lymphoid organs.

\section{Ikaros and Related TFs}

Ikaros is a member of a family of lymphoid-restricted zinc-finger TFs including Helios and Aiolos [14-16]. Through alternative splicing at least six different isoforms are produced, some of which (forms 4-6) lack one or more of the four zinc-fingers responsible for DNA binding [14, 17]. These forms probably function as naturally occurring dominant-negative forms.

The first attempts to produce Ikaros null-mutant mice generated mice lacking the DNA-binding zinc fingers 1-3, which resulted in a stable dominant-negative form of Ikaros (as was later shown) that can dimerize with other Ikaros-related proteins, such as Aiolos, but cannot bind DNA [18]. These mice lack all T, B, and natural killer (NK) cells and their progenitors, suggesting that Ikaros-related proteins are required for survival or development of common lymphoid stem cells.

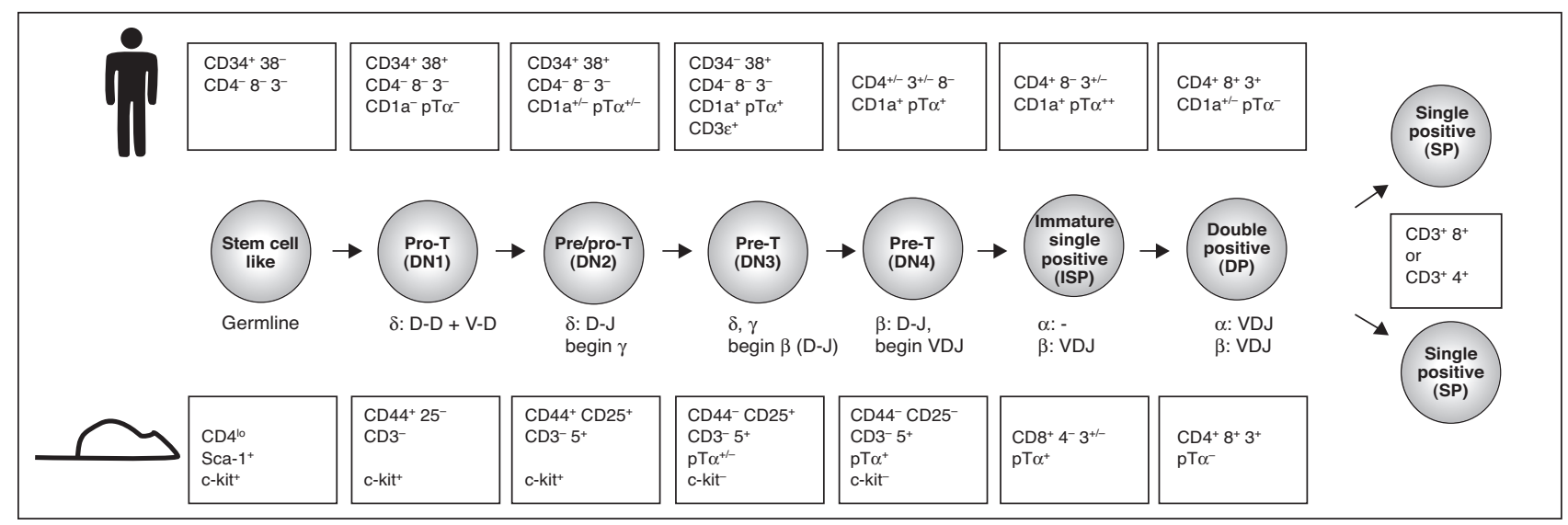

Figure $1 . T$ cell differentiation in the thymus. Depicted are the different stages in both human and mouse T cell development, indicating the surface markers of subpopulations and rearranagement of the TCR genes. Although different markers are used for the subpopulations in mouse and humans, the basic mechanisms are conserved. This figure has been designed to emphasize similarities rather than differences between species. 
Later on true Ikaros-null mice were produced by deleting the last coding exon, which contains the transactivation and dimerization domain [19]. In these mice B cell development is blocked, as initially is the case for T cell development. During fetal life, thymocytes are absent, but 5 days after birth they start to appear, and after a few weeks a thymus with normal cellularity has developed. However, there are fewer $\mathrm{CD}^{+} \mathrm{SP}$ cells, and $\gamma \delta \mathrm{T}$ cell development is affected. Mature T cells show hyperproliferation after TCR engagement [19]. A more detailed analysis revealed that DN1 and DN3 cells were decreased, but DN4 cells were not, suggesting that Ikaros members influence $\beta$-selection via the pre-TCR [20].

Several studies have shown that Ikaros, and its T cellspecific family member Aiolos, exert at least some of their function as transcriptional repressors. Ikaros proteins were shown to associate with heterochromatin in interphase nuclei, a region associated with transcriptionally silent genes [21, 22]. In T cells, Helios/Ikaros complexes were shown to associate with centromeric clusters, where transcriptionally silent genes are located. When thymocytes are not in cell cycle, or when mature $\mathrm{T}$ cells remain resting, no centromeric clustering of Ikaros protein was observed, but in cycling cells such clusters were readily observed. This suggests that Ikaros proteins keep genes silent by repositioning these genes to heterochromatin. Unfortunately, these studies did not investigate which forms of Ikaros (for instance the forms lacking zinc fingers) were present in these clusters.

\section{GATA-3}

GATA-3 was originally identified as a protein that binds to the TCR $\alpha$ gene enhancer [23]. GATA-3 is a member of a family of TFs that bind the GATA-consensus motif (T/A)GATA(A/G) through a highly conserved C-terminal C4 zinc finger binding domain [24]. The GATA family contains six members, two of which, GATA-1 and GATA-2, are expressed in various hematopoietic lineages. In contrast, GATA-4, -5 , and -6 are expressed in developing cardiac structures, in the gut, the urogenital system, smooth muscle cells, and in the brain. GATA-3 expression is abundant in the developing central nervous system, adrenal gland and kidney.

Within the hematopoietic system GATA-3 expression is confined to T lymphocytes and NK cells [23, 25-28]. GATA3 is expressed in early steps of mouse hematopoietic development, in the intraembryonic regions known to give rise to hematopoietic precursors [29]. When GATA-3 expression was evaluated in various hematopoietic progenitors purified by flow cytometry, expression was observed in hematopoietic stem cells, common lymphoid progenitors, pro-T and pre- $\mathrm{T}$ cells, but not in progenitors of the granulocyte/macrophage or megakaryocyte/erythrocyte lineage or in pro- or pre-B cells
[30]. The GATA-3 gene is already expressed in the earliest $\mathrm{CD} 25^{-} \mathrm{CD} 44^{+}$DN progenitors in day 12 fetal thymus [31]. Using mice with an insertion of a lacZ reporter in the GATA3 gene on one allele (GATA- $3^{\text {thlslac }}$ ), the proportion of GATA-3-expressing cells was quantified during T cell development [25]. GATA-3 expression was significant at the DN1 stage in the thymus. The two waves of TCR $\beta$ and TCR $\alpha$ gene recombination were associated with low proportions of GATA $-3^{+}$cells. The stage of rapidly proliferating DN4 and ISP cells, which insulates these two periods of TCR rearrangement, was characterized by a large proportion of GATA-3expressing cells [25]. The proportion of GATA $-3^{+}$cells, which was low in DP cells, increased with the onset of positive selection events, characterized by $\mathrm{CD} 3$ and TCR $\alpha \beta$ upregulation and CD69 expression, and reached its highest level at the $\mathrm{CD} 4^{+} \mathrm{CD} 8^{\text {low }} \mathrm{CD} 69^{+}$stage at which the $\mathrm{T}$ cells make the CD4/CD8 lineage commitment decision (R.W.H., unpublished results). GATA-3 expression remained high during the maturation of CD4 SP cells in the thymus, but is downregulated after commitment to the CD8 lineage, and is finally completely lost in mature $\mathrm{CD} 8{ }^{+}$cells in the periphery [25].

Mice with a targeted deletion of GATA-3 die between embryonic day 11 and 12, displaying massive internal bleeding, central nervous defects, and growth retardation [28]. Recently, it was reported that noradrenaline deficiency of the sympathetic nervous system is a major cause of the embryonic lethality [32]. Pharmalogical rescue of GATA- $3^{--}$fetuses beyond day 11 by feeding catechol intermediates to pregnant females revealed various abnormalities later in fetal development, including severe thymic hypoplasia at fetal day 16.5 [32].

Antisense GATA-3 oligonucleotides inhibited T cell development from fetal liver precursors in fetal thymic organ cultures (FTOC), indicating the critical importance of GATA3 for early $\mathrm{T}$ cell development [31]. Moreover, RAG-2-complementation experiments in vivo demonstrated that the development of GATA-3 $3^{--}$embryonic stem (ES) cell-derived $\mathrm{T}$ cell precursors is arrested at or before the DN stage [33]. In such GATA- $3^{--} / \mathrm{RAG}^{-2^{--}}$chimeric mice, the thymus contained only DN cells, in which the presence of GATA- $3^{-1-}$ ES cell-derived thymocytes could not be detected. In contrast, the GATA-3-deficient ES cells contributed significantly to nonhematopoietic tissues and the erythroid, myeloid, and B cell lineages. In chimeric mice generated by injection of GATA3-deficient lacZ-expressing ES cells in wild-type blastocysts, it was shown that GATA- $3^{-1-}$ ES cells did not contribute to the $\mathrm{T}$ cell lineage, not even to the earliest subset of $\mathrm{CD} 25^{-} \mathrm{CD} 44^{+}$ DN thymic progenitors [25]. Although GATA-3 activity could be required for the proliferation or survival of cells within this earliest DN cell population in the thymus, it seems more likely that GATA-3 is essential for the development of T-lineage-restricted progenitors in fetal liver and bone 
marrow. This would be supported by the observed expression of GATA-3 in common lymphoid progenitors [30] and the inhibition of in vitro $\mathrm{T}$ cell development from fetal liver precursors by antisense oligonucleotides [31]. Taken together, these findings demonstrate an essential role for GATA-3 in $\mathrm{T}$ cell commitment, comparable to the role of the TF Pax- 5 in B cell development [34].

The presence of GATA-3-binding sites has been described in the TCR $\alpha, \operatorname{TCR} \beta, \mathrm{TCR} \delta$, and $\mathrm{CD} 8 \alpha$ enhancers, and binding of GATA- 3 to these enhancers induced their activity [23, 35, 36], suggesting a role for GATA-3 in the regulation of TCR rearrangement or TCR transcription. The highest level of GATA-3 transcription was observed in the stage of rapidly dividing DN3 cells, which have passed $\beta$-selection, as well as in the DP cells during the positive selection phase [25]. In this context, the function of GATA3 might well parallel its function in the regulation of the Th2 cytokine locus, where GATA-3 acts by inducing chromatin remodeling during cellular proliferation. Alternatively, GATA-3 might be involved in the induction of cellular proliferation after the successful completion of TCR rearrangments. This hypothesis would be supported by findings for other GATA family members that implicate them in cell fate decisions by the induction of proliferation at the expense of differentiative potential [25].

\section{Basic Helix-Loop-Helix Proteins, Especially E-Box Proteins}

Basic helix-loop-helix (bHLH) proteins have been implicated in gene regulation during differentiation processes of many distinct cell types, including lymphoid cells.

The basic domain of the bHLH proteins is involved in DNA binding, whereas dimerization is mediated via the two helices separated by a loop. As dimerization is a prerequisite for proper DNA binding, the exact function of bHLH factors is dependent on their dimerization pattern. The bHLH TFs can be subdivided into several classes, based on their structure, dimerization potential, and/or function (Table 1) [37]. Class I proteins, also known as
E-box binding proteins or E proteins for their capacity to bind to E-box sequences (CANNTG) within regulatory elements, comprise E2A (or better its E47 and E12 splice forms), HEB, and E2-2, and also the Drosophila daughterless protein. These $\mathrm{E}$ proteins are able to form homodimers, but can also heterodimerize with the tissue-specific class II bHLH proteins, examples of which include MyoD, Myf5, and, for example, the human and mammalian homologues of the Drosophila protein achaete-scute (HASH, MASH). The class III proteins, of which c-Myc is the best studied example, contain a zip domain in addition to the bHLH domain and can form heterodimers with class IV bHLH-zip proteins like Mad and Max. The Id (inhibitor of DNA binding) proteins forming class $\mathrm{V}$ lack a basic DNA-binding domain, but can still heterodimerize with $\mathrm{E}$ proteins, thereby inhibiting proper binding of these factors to their target sequences. The class VI proteins are recognized on the basis of a Pro residue in the basic region; the HES-1 protein that functions downstream of Notch is an example of this type. Finally, class VII proteins, of which AHR is an example, contain a bHLH domain as well as a PAS domain.

Insight into the role of bHLH proteins in lymphoid and more specific $\mathrm{T}$ cell differentiation has largely come from studies on mice deficient in the E proteins E2A and HEB, and from transgenic mice overexpressing Id proteins, that act as inhibitors of E proteins. Collectively, these studies provide evidence that, contrary to, for example, myogenesis, E proteins themselves are the major bHLH factors regulating lymphoid differentiation and that tissue-specific (class II) bHLH TFs do not seem be involved. E2A-deficient mice display a complete block in B cell differentiation around the pro-B cell stage, prior to the occurrence of immunoglobulin (Ig) DH-JH rearrangements [38]. In addition to the $\mathrm{B}$ cell phenotype, $\mathrm{E} 2 \mathrm{~A}^{-1-}$ mice also exhibit a profound, though less severe, defect in $\mathrm{T}$ cell differentiation. On average these mice have fivefold fewer thymocytes, with a decrease in especially the $\mathrm{CD} 4^{+} / \mathrm{CD} 8^{+} \mathrm{DP}$ thymocyte population and a concomitant small increase in the $\mathrm{CD}^{+}$

\begin{tabular}{|lll|}
\hline \multicolumn{2}{|l|}{ Table 1. Classification of bHLH proteins } & \\
Class & Features & Examples \\
Class I & E proteins, which can homodimerize or heterodimerize with class II proteins & E2A, E2-2, HEB, da \\
Class II & tissue-specific bHLH proteins, which heterodimerize with class I proteins & MyoD, Myf 5, MASH, HASH, TAL1, as-c \\
Class III & bHLH-zip proteins & c-Myc, TFE3 \\
Class IV & bHLH-zip proteins which heterodimerize with class III proteins & Max, Mad \\
Class V & HLH proteins without basic domain, which heterodimerize with class I proteins, & Id1, Id2, Id3, Id4, emc \\
& thereby inhibiting class I DNA binding & \\
Class VI & bHLH proteins with Pro residue in basic region & HES-1, hairy/enhancer of split \\
Class VII & bHLH-PAS proteins & AHR \\
\hline
\end{tabular}


and especially the $\mathrm{CD}^{+} \mathrm{SP}$ cell populations [39]. The decrease in DP cells is due to a partial block in one of the earliest stages of thymocyte differentiation, the DN1 stage [39].

$\mathrm{HEB}^{-1-}$ mice also display a partial block in $\mathrm{T}$ cell differentiation next to a clear B cell differentiation defect [40]. This partial block in HEB-deficient mice is at the transition from DN to DP cells, which occurs later than in E2A-deficient mice [41]. Importantly, mice expressing a dominantnegative HEB protein show an earlier block at the DN stage [42]. The latter observation points towards an important role for E2A-HEB heterodimers in regulating differentiation processes in T cells, next to E2A and HEB homodimers. Indeed E47-HEB dimers have been observed as predominant complexes in T cells [39, 43], although detectable levels of both homodimers have also been found. Apparently, there is some level of redundancy between $\mathrm{E}$ proteins in $\mathrm{T}$ cells, and presumably not in B cells in which only high levels of predominantly E47 homodimers are found. This would then explain the remarkable difference in severity of the E2A defect for B- and T-lymphoid differentiation, in that a lack of E2A TFs in E2A-null mice can partially be compensated for by HEB proteins in differentiating $T$ cells, but not $B$ cells.

The third E protein, E2-2, has not been studied extensively in lymphoid cells. However, mice with a targeted deletion of the E2-2 gene do not exhibit a clear T cell phenotype, despite expression of E2-2 mRNA in thymocytes; this is in contrast to its presumed role in $\mathrm{B}$ cell differentiation, given the effect of E2-2 inactivation on the B cell phenotype [40].

Another series of studies stressing the central role of $\mathrm{E}$ proteins in differentiation of lymphocytes are those on transgenic mice constitutively expressing Id proteins, as well as studies in which FTOC are retrovirally transduced with Id proteins. Overexpression of the Id1 gene in mice results in impaired $\mathrm{B}$ cell differentiation at a stage similar to the block in E2A ${ }^{-1}$ mice [44], whereas the observed $\mathrm{T}$ cell phenotype of these mice with many DN cells resulted from massive apoptosis of differentiating $\mathrm{T}$ cells rather than a developmental block [45]. Transgenic mice overexpressing the Id2 HLH protein display a stage-dependent differentiation block with a significant increase in CD4-CD $8^{+}$ISP cells [46]. The constitutive Id2 level in these mice overrules normal Id2 downregulation at the ISP stage, thereby keeping E2A and HEB bound, resulting in a differentiation block and an increased proliferation at the stage with TCR $\beta$-chain rearrangements. Alternatively, the excess free Id2 levels per se might induce proliferation and block differentiation. The role of Id3 in thymocyte differentiation has been studied quite extensively. Retroviral transduction of human $\mathrm{CD} 34^{+} \mathrm{CD} 1 \mathrm{a}^{-}$progenitor cells with an $\mathrm{Id} 3$ encoding retrovirus was found to inhibit TCR $\alpha \beta$ T cell differentiation, but instead was found to promote the development of NK cells [47]. Transduction with Id3 of CD4+ ISP cells that are already committed to the $\mathrm{T}$ cell lineage showed that TCR $\alpha \beta$ but not TCR $\gamma \delta \mathrm{T}$ cell differentiation is severely disrupted [48]. In line with these findings, $\mathrm{Id}^{-{ }^{--}}$mice lack lymph nodes and show a greatly reduced population of NK cells [49]. Studies on Id $3^{--}$mice illustrate that Id3 is required for positive selection in thymocytes and that negative selection is severely perturbed when Id3 is lacking, thus identifying Id3 as an essential component for proper thymocyte differentiation [50]. Overall, data from the various studies on the role of Id HLH proteins suggest the importance throughout thymocyte differentiation of a delicate balance in the levels of $E$ proteins E2A and HEB on the one hand and Id factors on the other.

Further evidence for the importance of E proteins in lymphoid differentiation comes from a completely different set of observations. In human T cell acute lymphoblastic leukemias (T-ALL), several different chromosome aberrations are found in which class II bHLH TFs are involved. These include a microdeletion on chromosome $1 \mathrm{p} 32$ harboring the TAL1 or SCL gene [51], and translocations $\mathrm{t}(1 ; 7)(\mathrm{p} 32 ; \mathrm{q} 35)$ and $\mathrm{t}(1 ; 14)(\mathrm{p} 32 ; \mathrm{q} 11)$ both involving TAL1 [52, 53], $\mathrm{t}(7 ; 9)(\mathrm{q} 35 ; \mathrm{q} 32)$ involving TAL2 [54], $\mathrm{t}(7 ; 19)(\mathrm{q} 35 ; \mathrm{p} 13)$ involving LYL1 [55], and $\mathrm{t}(14 ; 21)(\mathrm{q} 11 ; \mathrm{q} 22)$ involving BHLHB1 [56]. As a result of all these aberrations, the involved bHLH genes will be juxtaposed to TCR gene regulatory elements and subsequently activated. Inappropriate expression may then lead to leukemic transformation in thymocytes, possibly (partly) through functional inactivation of $E$ proteins such as E2A and HEB that are required for proper thymocyte development. Oligomeric TF complexes in erythroid cells containing TAL1-E2A heterodimers as well as LMO1 and LMO2 proteins [57] illustrate the in vivo complexing potential of these factors. Moreover, TAL1 in concert with LMO1 can repress the transactivation potential of E2A proteins [58-60].

Further support for the E protein inactivation hypothesis comes from a recent study where aberrant expression of TAL1 and LMO1 in double transgenic mice leads to inactivation of E2A-HEB function, influences HEB-induced pre-TCR $\alpha$ (pre$\mathrm{T} \alpha$ ) chain expression, and alters thymocyte differentiation [61]. Consistent with this idea is the rapid development of lymphomas of immature $\mathrm{T}$ cell phenotype in $\mathrm{E} 2 \mathrm{~A}^{--}$mice as well as Id1 and Id2 transgenic mice $[39,45,46]$.

Together, all these data point towards a pivotal role for $\mathrm{E}$ proteins in lymphoid and especially $\mathrm{T}$ cell differentiation. Disruption of E2A and HEB through targeted deletion of the E proteins or functional inactivation via binding to constitutively expressed dominant-negative Id proteins or tissue-specific bHLH factors, as in human T cell leukemias, might block their function as key regulators in thymocyte differentiation. In addition, this inactivation model also predicts a block in the presumed tumor-suppressor function of E2A, resulting in the development of lymphomas. 
Originally, the E proteins have been identified as transcriptional regulators binding to $I G H$ and $I G K$ enhancer sequences [62]. Within these enhancers several E-box sequences can be discerned that act as the actual binding sites for E proteins. Full enhancer activity is required for transcription and recombination of $\mathrm{Ig}$ genes, suggesting that $\mathrm{E}$ proteins play an essential role in these processes. E2A is required for proper regulation of many B-lineage-specific genes, including RAG1, RAG2, $\lambda 5$, VpreB, EBF, and PAX-5 [63-66]. Analogous to Ig enhancers, E-box-binding sites have also been recognized in enhancers of the TCR $\delta / T C R \alpha$ locus as well as the TCR $\beta$ locus, suggesting a role for E proteins in regulation of TCR recombination similar to Ig rearrangement [67]. The observation that particular subsets of TCR $\gamma \delta$ cells are lacking in E2 $\mathrm{A}^{-1-}$ mice is in support of this idea; such E2A-regulated differential accessibility to the recombination enzymes seems to be E2A dosage-dependent [68].

Further evidence comes from experiments using human kidney cells, in which $T C R G(\mathrm{~V} \gamma-\mathrm{J} \gamma)$ as well as only the immature incomplete type of TCRD rearrangements (D $\delta 2-$ $\mathrm{D} \delta 3$ and $\mathrm{V} \delta 2-\mathrm{D} \delta 3$ ) can be induced upon E2A or HEB introduction in the presence of RAG activity (Langerak et al., submitted). The inability to detect $J \delta 1$ rearrangements in this system is in line with observations that in vitro E47 cannot bind to the TCRD enhancer [69], which is thought to regulate accessibility to the $\mathrm{J} \delta$ region. E47 is, however, able to bind the TCRA enhancer, whereas transactivation of the endogenous TCRA enhancer could be inhibited by the class II bHLH factor TAL1 [69]. E2A-HEB heterodimers are also known to interact with the CD4 enhancer and regulate its activity in $\mathrm{T}$ cells [43]. Furthermore, in line with earlier described results, thymic RAG activity was found to be several-fold lower in E2A-deficient mice, suggestive of E protein-mediated regulation of RAG genes in relation to TCR recombination in T cells [70]. In addition to the above-described regulatory effects of E proteins on rearrangement processes, E2A was also suggested to be involved in growth regulation processes. The finding that overexpression of E2A in NIH3T3 cells promoted growth arrest could be explained by transcriptional activation of the cyclin-dependent kinase inhibitor p21/CIP1 gene by E2A [71]. Enhanced expression of class I bHLH proteins in $293 \mathrm{~T}$ cells resulted in apoptosis induction leading to a decreased proliferation rate [72]. Furthermore, expression of Id proteins in fibroblasts induced cell cycle progression, most probably through inhibition of E-box-binding proteins [73]. Inactivation of E2A leading to inhibition of cell cycle arrest might thus well be (part of) the mechanism by which the disruption of the presumed tumor-suppressor effect of E2A and subsequent transformation of lymphoid cells can occur.

As illustrated above, E proteins have thus been implicated in regulating gene rearrangement and growth control processes in lymphoid cells. An important question remaining is, which mechanism or signaling event regulates E protein activity, or better, the ratio between E-box stimulating activity and Id inhibitory activity, in differentiating $\mathrm{T}$ cells. Although not much is known about this type of regulation, one candidate regulator might be the Notch protein, which is located in the membrane but acts as transcriptional activator following proteolytic cleavage. Notch signals seem to function via inhibition of E2A-regulated promoters, whereas the phenotype of mice overexpressing Notch-1 is similar to that of E2A-deficient mice [74]. Notch activation via its downstream target HES-1, which is a class VI bHLH factor, has been suggested to be required for $\mathrm{T}$ cell development, whereas in its absence cells would choose a B cell fate [74]. In Hes- $1^{-/-}$mice T cell development is indeed arrested at the DN1 stage [75, 76].

\section{Tcf/Lef Proteins}

Tcf-1 is the prototypic member of a family of proteins containing an HMG-box as the DNA-binding domain [7781]. These include Lef-1, Tcf-3, and Tcf-4. Lef-1 is present not only in T cells but also in immature B cells [80], whereas Tcf- 1 is highly $\mathrm{T}$ cell-specific in adult mice. The functions of Tcf-3 are not well characterized, whereas Tcf-4 plays a vital role in maintenance of the stem cell compartment in the gut [82]. Reconstitution of lethally irradiated mice with $\mathrm{Tcf}^{-/-}$fetal liver stem cells resulted in mice with normal $\mathrm{T}$ and $\mathrm{B}$ cell development, indicating that Tcf-4 is not required for T (or B) cell development (Staal, O'Toole, Meeldijk, Clevers, unpublished observations).

Two different Tcf-1 mutant mice have been generated [83]. In $\operatorname{Tcf}(\mathrm{V})$ mutant mice, a low level of a truncated yet functional Tcf-1 is still expressed, whereas the Tcf(VII) mutation abolishes the DNA-binding activity of TCF-1 completely and presumably induces a null-phenotype. Disruption of Tcf-1 in Tcf (VII) mutant mice results in a block in T cell development at the ISP to DP transition [83] and within the DN compartment at the $\mathrm{CD} 44^{+} \mathrm{CD} 25^{-}$to $\mathrm{CD} 44^{+} \mathrm{CD} 25^{+}$transition [84]. Importantly, cells in the DN2 and ISP stages are apparently not proliferating [84]. Thymocyte development is not completely blocked because of the compensatory role of Lef-1. Both Tcf-1 mutations have been crossed into the Lef-1 mutant mouse strain. Lef- $1^{-1-}$ mice have several developmental defects, including a defect pro-B cell differentiation, but develop to term and display normal thymocyte development [85]. While Tcf (V) mutant mice are viable and have modestly impaired thymocyte development, Lef-1/Tcf (V) double-mutant mice display a complete block in thymocyte development at the ISP stage [86]. Lef- $1^{-/-}$Tcf (VII) ${ }^{-1-}$ mice die at E10 [87] with dramatic developmental defects affecting the limb buds and neural tube. T cell development can obviously not be studied in these embryos. 
Remarkably, in 4-6-month-old Tcf-1 null mice, thymocyte development is completely blocked at the DN1 stage. Moreover, Tcf-1 knockout (KO) bone marrow stem cells can give rise to all hematopoietic lineages except $\mathrm{T}$ cells in radiation chimeras ([84] and Staal, Meeldijk, and Clevers, unpublished observations). Taken together, Tcf-1 is required for the earliest stages of adult $\mathrm{T}$ cell development, but in fetal thymopoiesis its requirement is less stringent.

Tcf- 1 is not an active TF by itself, but requires the interaction with the Wnt effector $\beta$-catenin [88]. Until recently, it was unknown which signal transduction routes control Tcf-dependent transcription, but they are likely to act by ultimately providing $\beta$-catenin in the nucleus to interact with its partner Tcf-1 to activate target genes. Signals operating on DN thymocytes, such as the preTCR and the cytokines interleukin 7 (IL-7) and stem cell factor, do not activate Tcf-dependent transcription [89]. We now know that Wnt signaling activates Tcfdependent transcription in thymocytes. Thus, the signaling route for a TF involved in T-lymphoid development has now been identified.

$\beta$-catenin is a known component of the Wnt signaling cascade [90]. Wnt proteins constitute a large (>19 members) family of extracellular signaling molecules that are found in many different species and influence cell fate and cell behavior during development. Among the best-studied effects of Wnt are the determination of segment polarity in Drosophila and the specification of the body axis in Xenopus [90].

Figure 2. Wnt signaling pathway. Wnt binds to a Frizzled receptor via a cysteine rich domain (CRD). Soluble Frizzled receptors (sometimes referred to as Frzb) occur that act as dominant negative molecules of Wnt signaling. In absence of Wnt, $\beta$-catenin is phosphorylated by GSK3 $\beta$ or a related

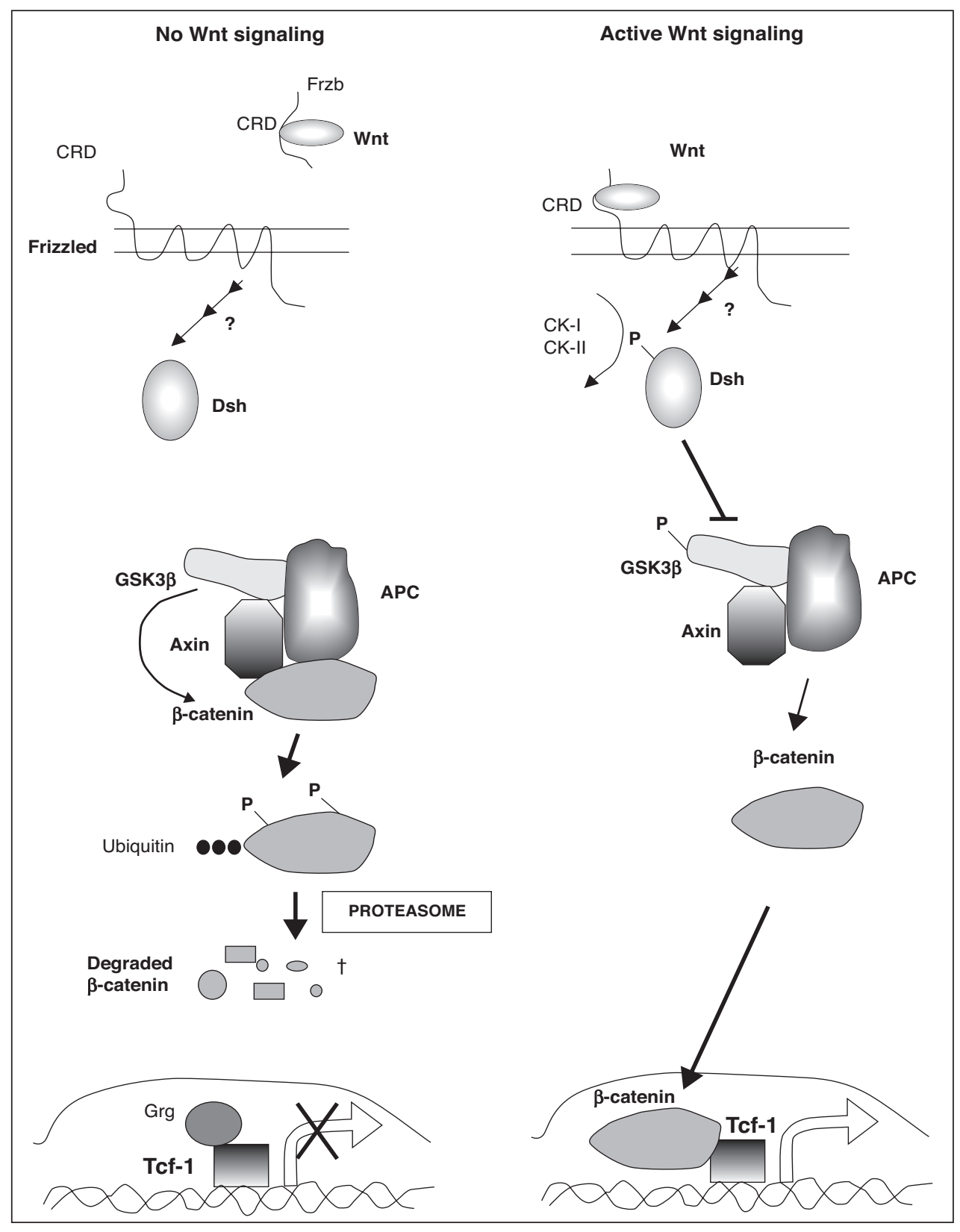

kinase, leading to its ubiquitinylation and degradation. Tcf-1 is inactive, and bound by Grg repressors in the nucleus. Binding of Wnt to Fz lead to inactivation of GSK3 $\beta$ via Dsh. $\beta$-catenin is not (hyper) phosphorylated and migrates to the nucleus, where it binds to Tcf-1 to activate target genes.
Deregulation of Wnt signaling has been shown to occur in several human cancers through mutations in key molecules of the Wnt pathway, including $\beta$-catenin [91, 92]. Wnt function as ligands for members of the Frizzled (Fz) family of serpentine receptors. Wnt binding to Fz initiates a complex signaling cascade that culminates in nuclear translocation of $\beta$-catenin (Fig. 2), that can then interact with members of the Tcf/Lef family to activate transcription of target genes [91, 93, 94].

In the absence of Wnt signals, a negative regulatory kinase, GSK3 $\beta$, acts by inducing phosphorylation of $\beta$ catenin [95] and its subsequent degradation via the ubiquitin/proteasome pathway [96] (Fig. 2). Both $\beta$-catenin and 
GSK3 $\beta$ are present in a complex with axin and the adenomatous polyposis coli tumor-suppressor protein [97]. In the absence of $\beta$-catenin in the nucleus, Tcf may recruit members of the Grg/groucho family, which act as global repressors of transcription [98]. Upon Wnt signaling, dishevelled (Dsh) is activated via unknown mechanisms, possibly involving phosphorylation via casein kinase I and II (CKI, CKII) $[99,100]$. Activated Dsh inactivates the activity of GSK3 $\beta$, leading to hypo- or dephosphorylation of $\beta$-catenin and its subsequent accumulation and nuclear import. In most reviews, this accumulation of $\beta$-catenin has been seen as important for transducing Wnt signals [101]; however, recent data suggest that it is not the high levels of $\beta$-catenin, but the dephosphorylation of critical residues in its $N$-terminus that regulate the signaling activity of $\beta$-catenin (Staal, van Noort, and Clevers, manuscript in preparation). For instance, artificial accumulation of $\beta$-catenin via pharmacological inhibition of its breakdown (a Wnt-independent way to increase $\beta$-catenin levels) does not activate Tcf-dependent transcription. Thus, there is no direct correlation between levels of $\beta$-catenin and activation of the Wnt-responsive TF Tcf.

In certain cell types such as fibroblasts, inhibition of GSK3 $\beta$ (for instance by treatment with lithium, a known GSK3 $\beta$ inhibitor) is sufficient to activate transcription of Tcf reporter genes, thereby mimicking Wnt signaling [89]. However, in T cells, inhibition of GSK3 $\beta$ is insufficient to activate Tcf-dependent transcription [89]. Recent experiments using highly sensitive reporter genes have, however, shown that lithium can induce Tcf-dependent transcription in T cells, but not as strongly as in fibroblasts (van Noort, Clevers, unpublished observations). This suggests a difference in regulation of Wnt signaling between T lymphocytes and fibroblasts, perhaps because of differential regulation of GSK3 $\beta$ activity or the involvement of another, not yet identified, kinase in $\mathrm{T}$ cells.

A recent study has shown that Wnt can activate Tcf-controlled transcription in thymocytes, and subsequently, that Wnt signals are required for normal $\mathrm{T}$ cell development [102]. Retroviral expression of soluble Wnt receptor mutants that block Wnt signaling, in combination with FTOC, showed that thymocyte differentiation was inhibited at the DN to DP transition [102]. These results imply an important role for the Wnt cascade in early thymocyte development. Moreover, transduction of fetal thymocytes with Wnt1 and Wnt4 resulted in increased survival or increased proliferation in an in vitro cell culture system [102]. This shows that Wnt signals are growth factors for pro- and pre-T cells.

Other studies have shown that Wnt signaling also functions as a growth factor for hematopoietic stem cells [103] and pro B cells [104], where Lef-1 is the Wnt-responsive TF. In light of the redundancy between Tcf- 1 and Lef- 1 during T cell development, we propose that both Tcf-1 and Lef-1 can serve to transduce Wnt signals in developing thymocytes.

Another TF with an HMG box which is not part of the TCF family, Sox 4, has been investigated. While these mice mainly have cardiac and B cell developmental defects, they have some problems in T cell development as well [105, 106]. FTOC with Sox $4^{-/-}$thymi demonstrated an impaired transition of DN to DP cells.

\section{HES-1, CBF-1, and the Notch Signaling Pathway}

As mentioned above, HES-1 is a TF of the class VI bHLH family. HES-1 is expressed in both thymocytes and thymic stromal cells [75], and its expression in thymocytes is regulated by Notch signaling.

Notch was first identified in Drosophila as a gene that plays a critical role in regulating cell fate decisions during neuronal and epidermal cell differentiation [107]. In mammals, four Notch homologs have been identified (Notch 1-4), that function as receptors interacting with Notch ligands, that are also transmembrane receptors of the so-called DSL (Delta/Serrate/lag2) family and comprise Jagged1/Serrate1, Jagged2/Serrate2, Delta1, Delta2, and Delta3 [108]. Interactions between cells expressing Notch and cells expressing DSL ligands result in proteolytic cleavage of Notch, releasing its intracellular domain, that translocates to the nucleus and interacts with the CBF-1/RBP-Jк TF, converting it from a repressor to an activator of gene transcription [109, 110] ( Fig. 3). The targets of activated CBF1/RBP-J $\kappa$ are incompletely characterized but include the hairy enhancer of split (HES) genes, that are upregulated by Notch and in turn downregulate the activity of certain bHLH TFs.

Recent data suggest that Notch signaling and HES-1 may play a critical role in promoting progression through several major checkpoints during $\mathrm{T}$ cell development, including the choice of committing to the $\mathrm{T}$ cell rather than the $\mathrm{B}$ cell lineage, the choice between the $\alpha \beta$ and $\gamma \delta$ lineages and, in the case of $\alpha \beta$ T cells, the choice between the $\mathrm{CD} 4^{+}$and $\mathrm{CD} 8^{+}$ lineages [111].

Tomita and coworkers [75] found that transfer of HES-1-1fetal liver cells into RAG2 ${ }^{--}$host mice normally reconstituted $\mathrm{B}$ cells but failed to generate mature $\mathrm{T}$ cells in the thymus. In the reconstituted thymus, $\mathrm{T}$ cell differentiation was arrested at DN1 (partially) and the early DN3 stage. The cause of these blocks is unknown, but is speculated to be due to a defect in the proliferative expansion of DN1 and DN2 thymocytes [75]. Thymocytes in the HES-1 ${ }^{-1-}$ reconstituted mice express $\mathrm{T}$ cell markers, which is in contrast to experiments with inducible deletion of Notch-1. In these experiments the majority of the DN1 cells in the thymus expressed markers of the B cell lineage and phenotypically resembled immature bone marrow $\mathrm{B}$ cells [112]. These results suggest that HES-1, in contrast to 
Figure 3. Notch signaling. The Notch receptor is processed in the Golgi by Furin and Fringe genes and expressed at the plasma membrane. Upon interaction with ligand (Delta or Jagged), Notch is cleaved by two different proteases (ADAM family proteases and Presenilin). The intracellular domain of Notch migrates to the nucleus via unknown mechanisms and interacts with the CBF-1 TF. The Notch-IC, CBF-1 complex activates transcription of HES genes and others.

Notch signaling, does not appear to play an obligatory role in commitment to the $\mathrm{T}$ cell lineage, and that other TFs downstream of Notch are likely to be involved in Notch-regulated commitment.

Additional evidence for a role for Notch in T cell lineage commitment comes from

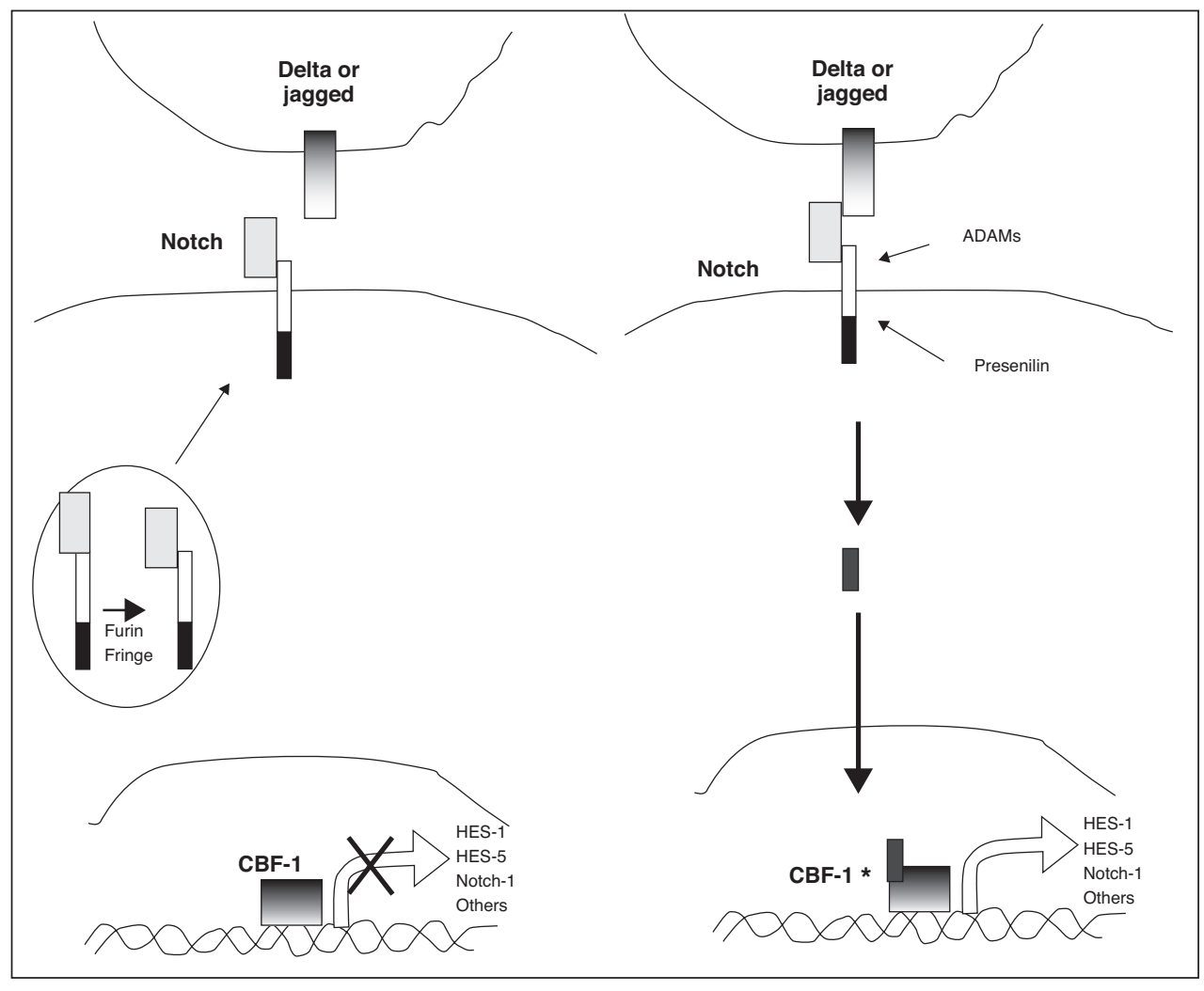
experiments in which bone marrow stem cells expressing constitutively active Notch-1 were used to reconstitute irradiated hosts. In these mice differentiation of stem cells into the B cell lineage was completely blocked and a thymusindependent population of $\mathrm{T}$ cells developed in the bone marrow [74]. Thus, lymphoid precursor cells develop into T cells via Notch signaling, but in the absence of such signals choose a B cell fate. Notch signals may function by inhibiting E2A activity, as Notch signals have been shown to block activation of an E2A-regulated promoter via induction of HES-1 [74, 113]. Indeed the phenotype of the $\mathrm{E} 2 \mathrm{~A}^{-/-}$mice is very similar to the phenotype of mice derived by overexpression of activated Notch-1 in bone marrow precursors.

Furthermore, a role for Notch in T cell lineage development is suggested by the finding that the Notch-1 gene is involved in chromosomal translocations with the TCR $\beta$ gene in a subset of cases of human T-ALL [114].

In addition to a role during the DN stage of T cell development, it was proposed that HES-1 functions to regulate the $\mathrm{CD}^{+}{ }^{+}$versus $\mathrm{CD} 8^{+}$cell fate choice. The expression of CD4 is developmentally regulated, in part, by a silencer element that prevents its expression in DN and $\mathrm{CD}^{+} \mathrm{SP}$ thymocytes [115, 116]. HES-1 has been found to bind to this CD4 silencer in vitro. In addition, overexpression of HES-1 inhibited transcription from a reporter construct containing CD4 regulatory elements and inhibited the expression of endogenous CD4 in T cell clones [113]. However, the physiological significance of

these results is unclear. There was no difference in the level of expression of HES-1 between $\mathrm{CD}^{+}$and $\mathrm{CD}^{+} \mathrm{T}$ cell clones, and the binding of HES-1 to the CD4 silencer was detected in T cell clones that express CD4, indicating that this may not be a functionally significant interaction. The authors also mentioned that expression of HES-1 in transgenic mice does not enhance $\mathrm{CD}^{+}$SP development. However, a role for Notch1 signaling in this binary cell fate decision is suggested by in vivo results in which Notch1 transgenic expression influences CD4 versus CD8 T cell fate [117].

While there is no experiment to support a role for HES1 in $\alpha \beta$ versus $\gamma \delta$ T cell lineage commitment, Notch signaling has clearly been shown to be involved in this process. This was first suggested by analysis of mice reconstituted with a mixture of bone marrow stem cells derived from Notch- $1^{+/+}$and Notch- $1^{+/-}$mice [111]. Both subpopulations contributed equally to the $\mathrm{B}$ cell lineage, however the Notch- $1^{+/-}$stem cells contributed less than the Notch- $1^{+/+}$ stem cells to the $\alpha \beta \mathrm{T}$ cell lineage. Second, analysis of $\mathrm{T}$ cell development in transgenic mice expressing constitutively active Notch-1 showed that, although the number of $\gamma \delta \mathrm{T}$ cells in these mice was normal, a higher percentage of them expressed CD4 and CD8, markers usually found on $\alpha \beta \mathrm{T}$ cells, and only rarely on $\gamma \delta$ cells [111].

From the studies described above, we conclude that Notch signaling has an essential role during several stages of $\mathrm{T}$ cell development. Although HES-1 has been shown to be involved 
in the maturation of DN thymocytes and the regulation of CD4/CD8 lineage commitment, other TFs downstream of Notch-1 remain to be identified.

\section{Other TFs}

Several other TFs that have fairly subtle effects on $T$ cell development in the thymus have been described. These include TFs originally identified in the II 2 minimal promoter such as the NF-KB/Rel factors and NF-AT, but also other factors such as CREB.

The NF-kB TF family includes NF-кB1 (p50/p105), NFКB2 (p52/p100), RelA (p65), c-Rel, and RelB. These TFs play important roles in regulation of inflammatory responses, cell proliferation and apoptosis $[118,119]$. The activity of NF- $\kappa \mathrm{B}$ proteins is controlled by cytoplasmic inhibitors of the IKB family. Given their important role in immune responses in mature lymphocytes, it was anticipated that they also are important for T cell development. This turned out not to be the case. Only RelB KO mice show defects in the development of thymic dendritic cells and medullary epithelial cells, but not of thymocytes [120, 121]. All other NF-KB family KO mice display normal $\mathrm{T}$ cell differentiation, although it remains possible that redundancy exists between family members. Double or even triple $\mathrm{KO}$ mice will have to answer this question.

NF-AT (nuclear factor of activated T cells) was identified as an inducible TF complex in the IL-2 enhancer by Crabtree and colleagues [122, 123]. NF-AT consists of a cytoplasmic component present in resting $\mathrm{T}$ cells, which can be any of four known NF-AT genes (NF-ATp, NF-ATc, NF-AT3, and NFAT4). The nuclear component of the complete NF-AT complex is AP1, consisting of dimers of Fos and Jun proteins. Upon $T$ cell activation, the protein phosphatase Calcineurin is activated, leading to dephosphorylation and subsequent nuclear transport of NF-AT.

While NF-ATp-deficient mice have normal thymocyte development [124], mice with a targeted mutation in the closely related NF-ATc gene show a defect in T cell differentiation. NF-ATc ${ }^{--}$mice are embryonic lethal, therefore NF$\mathrm{ATc}^{--}$ES cells were used in a $\mathrm{RAG}^{-1-}$ complementation assay $[125,126]$. The thymus of these $\mathrm{RAG}^{--} \mathrm{NF}^{-\mathrm{ATc}^{--}}$ mice had decreased cellularity and a partial block in the ISP to DP transition. Thus, although NF-ATc and NF-ATp are closely related proteins with similar expression patterns, they play differential roles in early T cell development. Presumably NF-ATc and NF-ATp bind to sites in the promoters of different target genes, or with differential affinity to the same sites.

CREB (cAMP response element binding protein) is a basic/leucine zipper TF binding to a cAMP response element (CRE) which is present in promoter/enhancer sequences of several T cell-specific genes, such as TCR $\alpha$, TCR V $\beta$, CD $3 \delta$, and $\mathrm{CD} 8 \alpha$, but also in many non-T cell genes [127, 128].
After cell stimulation, CREB is phosphorylated on serine 113, causing its interaction with the coactivator $\mathrm{CBP}$, subsequently leading to transcriptional activation. CREB dominant-negative transgenic mice who carry a serine 113 mutation, have relatively normal $\mathrm{T}$ cell development, but increased apoptosis $[129,130]$. This increased apoptosis is due to a $\mathrm{G}_{1}$ cell cycle arrest [129], that in turn was related to a decreased induction of AP-1. AP-1 is involved in induction of cytokines required for cell cycle progression and proliferation.

\section{Concluding Remarks and Future Perspectives}

During the last 2-3 years, attention of researchers working on $\mathrm{T}$ cell development has focused more on the $\mathrm{CD} 4{ }^{-} \mathrm{CD} 8^{-}$ DN stage than before. The realization that this small subset in the adult thymus can be subdivided in several subpopulations, underlying several key developmental checkpoints including commitment towards the $\mathrm{T}$ cell lineage, has spurred a large number of studies into the biology of these cells. It is clear that most of the TFs discussed here also play a major role in the development of the different DN populations. Through the use of "KO" and conditional KO mice, insight into the role of these TFs in T cell development has greatly increased. Table 2 summarizes the phenotype of these KO mice.

Clearly it is important to investigate how the different TFs interact with each other, if they control the same target genes, or if one factor is target gene of another factor. It is clear that Notch signaling stimulates $\mathrm{T}$ cell development, while inhibiting B cell developmental choices. In part this is accomplished by downregulation of E2A genes via induction of HES-1. How does this repression work? And how does Notch exert its other effects, that are not mediated via HES-1, but presumably via other (transcription?) factors? If GATA-3 might be a target of Ikaros, how is this regulated? In Drosophila, Notch and wingless signaling converge. Is there a similar crosstalk between Notch and Wnt signaling in thymocyte differentiation? And by inference, between CBF1/HES factors and Tcf/LEF?

For Tcf-1 we have some idea of the signal transduction routes leading to transcriptional activation (although clearly not all players are known yet), and indications as to how E2A is regulated have emerged. But we have no idea of the signaling routes, if any, controlling Ikaros, GATA-3, HEB, or Sox4. Identification of interacting protein partners is important to discover not only how transactivation and repression by these TFs occur, but also to start elucidation of these signaling routes. These studies are complex, and become even more complex when one realizes that these factors often have different splice variants, or are part of a multi-gene family displaying redundancy in function.

Besides signal transduction routes and interacting partners, the issue of target genes is an important one in order 


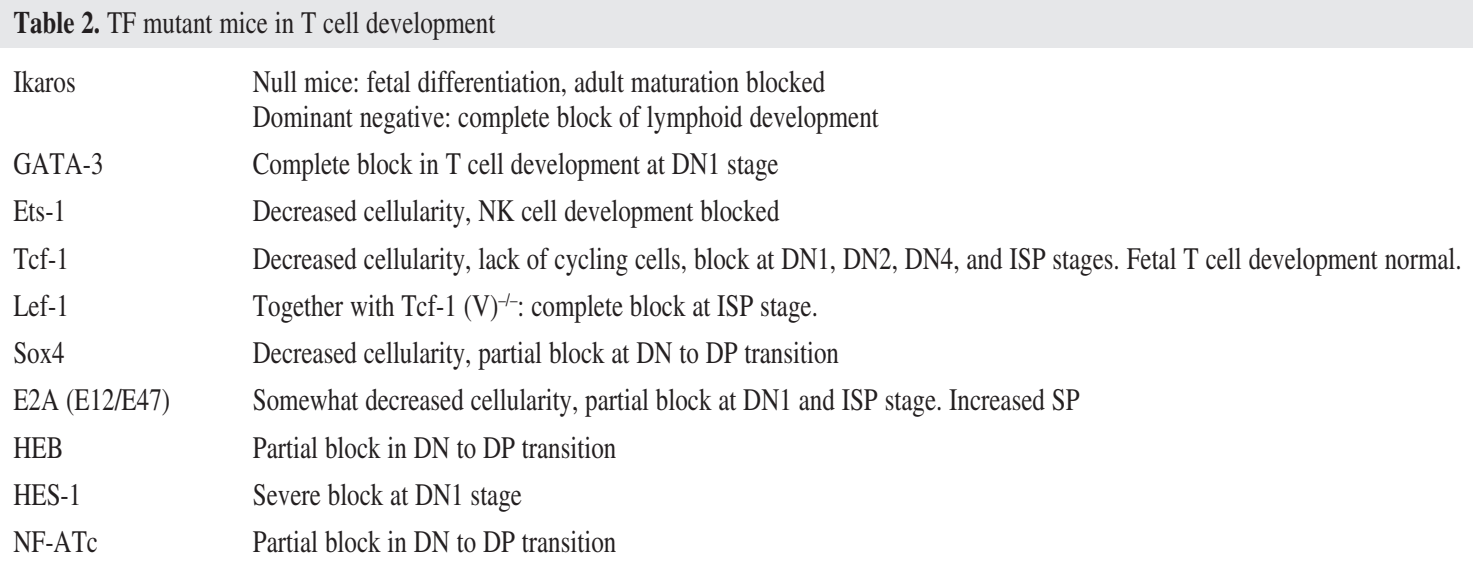

to understand the function of these TFs in T cell development. Very little is known in this respect, but a great deal of research effort is devoted to this topic.

Two recent developments in research on lymphoid differentiation may help answer the above questions: first, the application of knowledge from model organisms such as Drosophila, C. elegans, and zebrafish to T cell development. Many molecules and signaling routes are conserved, allowing some extrapolation of functions and pathways. For instance, besides the already mentioned Wnt and Notch pathways, the Hedgehog (Hh) pathway has recently been shown to regulate differentiation of DN cells as well [131]. The Hh, wingless/Wnt, and Notch pathways were all originally discovered in Drosophila. A second important tool to help our understanding of $\mathrm{T}$ cell development may come from the use of genomics data via DNA microarrays. With the murine and human genomes fully sequenced, whole genome approaches will undoubtedly generate new knowledge of $\mathrm{T}$ cell development and possibly lead to opportunities for therapeutic manipulation of $\mathrm{T}$ cell function.

\section{ACKNOWLEDGMENT}

We thank Dr. J.J.M. van Dongen for stimulating discussions. F.J.T.S. is a fellow of the Dutch Royal Academy of Sciences (KNAW).

\section{REFERENCES}

1 Ernst P, Smale ST. Combinatorial regulation of transcription. I: General aspects of transcriptional control. Immunity 1995;2:311-319.

2 Kao HY, Ordentlich P, Koyano-Nakagawa N et al. A histone deacetylase corepressor complex regulates the Notch signal transduction pathway. Genes Dev 1998;12:2269-2277.

3 Zhou S, Fujimuro M, Hsieh JJ et al. SKIP, a CBF1-associated protein, interacts with the ankyrin repeat domain of NotchIC to facilitate NotchIC function. Mol Cell Biol 2000;20:2400-2410.

4 Hsieh JJ, Zhou S, Chen L et al. CIR, a corepressor linking the DNA binding factor CBF1 to the histone deacetylase complex. Proc Natl Acad Sci USA 1999;96:23-28.

5 Billin AN, Thirlwell H, Ayer DE. Beta-catenin-histone deacetylase interactions regulate the transition of LEF1 from a transcriptional repressor to an activator. Mol Cell Biol 2000;20:6882-6890.

6 Osborne BA. Transcriptional control of T cell development. Curr Opin Immunol 2000;12:301-306.

7 Rothenberg EV. Stepwise specification of lymphocyte developmental lineages. Curr Opin Genet Dev 2000;10:370-379.

8 Clevers H, Ferrier P. Transcriptional control during T cell development. Curr Opin Immunol 1998;10:166-171.
9 Kuo CT, Leiden LM. Transcriptional regulation of T lymphocyte development and function. Ann Rev Immunol 1999;17:149-187.

10 Staal FJT, Clevers HC. Tcf/Lef transcription factors during $\mathrm{T}$ cell development: unique and overlapping functions. Hemat J 2000;1:1.

11 Kondo M, Weissman IL, Akashi K. Identification of clonogenic common lymphoid progenitors in mouse bone marrow. Cell 1997;91:661-672.

12 Capone M, Hockett RD, Zlotnik A. Kinetics of T cell receptor beta, gamma, and delta rearrangements during adult thymic development: $\mathrm{T}$ cell receptor rearrangements are present in CD44(+)CD25(+) Pro-T thymocytes. Proc Natl Acad Sci USA 1998;95:12522-12527.

13 Shortman K, Wu L. Early T lymphocyte progenitors. Annu Rev Immunol 1996;14:29-47.

14 Georgopoulos K, Moore DD, Derfler B. Ikaros, an early lymphoid-specific transcription factor and a putative mediator for $\mathrm{T}$ cell commitment. Science 1992;258:808-812.

15 Kelley CM, Ikeda T, Koipally J et al. Helios, a novel dimerization partner of Ikaros expressed in the earliest hematopoietic progenitors. Curr Biol 1998;8:508-515. 
16 Morgan B, Sun L, Avitahl N et al. Aiolos, a lymphoid restricted transcription factor that interacts with Ikaros to regulate lymphocyte differentiation. EMBO J 1997;16:2004-2013.

17 Molnar A, Georgopoulos K. The Ikaros gene encodes a family of functionally diverse zinc finger DNA-binding proteins. Mol Cell Biol 1994;14:8292-8303.

18 Georgopoulos K, Bigby M, Wang JH et al. The Ikaros gene is required for the development of all lymphoid lineages. Cell 1994;79:143-156.

19 Wang JH, Nichogiannopoulou A, Wu L et al. Selective defects in the development of the fetal and adult lymphoid system in mice with an Ikaros null mutation. Immunity 1996;5:537-549.

20 Winandy S, Wu L, Wang JH et al. Pre-T cell receptor (TCR) and TCR-controlled checkpoints in T cell differentiation are set by Ikaros. J Exp Med 1999;190:1039-1048.

21 Brown KE, Guest SS, Smale ST et al. Association of transcriptionally silent genes with Ikaros complexes at centromeric heterochromatin. Cell 1997;91:845-854.

22 Cobb BS, Morales-Alcelay S, Kleiger G et al. Targeting of Ikaros to pericentromeric heterochromatin by direct DNA binding. Genes Dev 2000;14:2146-2160.

23 Ho IC, Vorhees P, Marin N et al. Human GATA-3: a lineagerestricted transcription factor that regulates the expression of the T cell receptor alpha gene. EMBO J 1991;10:1187-1192.

24 Yamamoto M, Ko LJ, Leonard MW et al. Activity and tissue-specific expression of the transcription factor NF-E1 multigene family. Genes Dev 1990;4:1650-1662.

25 Hendriks RW, Nawijn MC, Engel JD et al. Expression of the transcription factor GATA-3 is required for the development of the earliest T cell progenitors and correlates with stages of cellular proliferation in the thymus. Eur J Immunol 1999;29:1912-1918.

26 George KM, Leonard MW, Roth ME et al. Embryonic expression and cloning of the murine GATA-3 gene. Development 1994;120:2673-2683.

27 Oosterwegel M, Timmerman J, Leiden J et al. Expression of GATA-3 during lymphocyte differentiation and mouse embryogenesis. Dev Immunol 1992;3:1-11.

28 Pandolfi PP, Roth ME, Karis A et al. Targeted disruption of the GATA3 gene causes severe abnormalities in the nervous system and in fetal liver haematopoiesis. Nat Genet 1995;11:40-44.

29 Manaia A, Lemarchandel V, Klaine M et al. Lmo2 and GATA3 associated expression in intraembryonic hemogenic sites. Development 2000;127:643-653.

30 Akashi K, Kondo M, Weissman IL. Role of interleukin-7 in $\mathrm{T}$ cell development from hematopoietic stem cells. Immunol Rev 1998;165:13-28.

31 Hattori N, Kawamoto H, Fujimoto S et al. Involvement of transcription factors TCF-1 and GATA-3 in the initiation of the earliest step of $\mathrm{T}$ cell development in the thymus. J Exp Med 1996;184:1137-1147.

32 Lim KC, Lakshmanan G, Crawford SE et al. Gata3 loss leads to embryonic lethality due to noradrenaline deficiency of the sympathetic nervous system. Nat Genet 2000;25:209-212.
33 Ting CN, Olson MC, Barton KP et al. Transcription factor GATA-3 is required for development of the T cell lineage. Nature 1996;384:474-478.

34 Nutt SL, Heavey B, Rolink AG et al. Commitment to the Blymphoid lineage depends on the transcription factor Pax5. Nature 1999;401:556-562.

35 Henderson AJ, McDougall S, Leiden J et al. GATA elements are necessary for the activity and tissue specificity of the Tcell receptor beta-chain transcriptional enhancer. Mol Cell Biol 1994;14:4286-4294.

36 Ko LJ, Engel JD. DNA-binding specificities of the GATA transcription factor family. Mol Cell Biol 1993;13:40114022.

37 Massari ME, Murre C. Helix-loop-helix proteins: regulators of transcription in eukaryotic organisms. Mol Cell Biol 2000;20:429-440.

38 Bain G, Maandag EC, Izon DJ et al. E2A proteins are required for proper B cell development and initiation of immunoglobulin gene rearrangements. Cell 1994;79:885-892.

39 Bain G, Engel I, Robanus Maandag EC et al. E2A deficiency leads to abnormalities in alphabeta T-cell development and to rapid development of T-cell lymphomas. Mol Cell Biol 1997;17:4782-4791.

40 Zhuang Y, Cheng P, Weintraub H. B-lymphocyte development is regulated by the combined dosage of three basic helix-loop-helix genes, E2A, E2-2, and HEB. Mol Cell Biol 1996;16:2898-2905.

41 Barndt R, Dai MF, Zhuang Y. A novel role for HEB downstream or parallel to the pre-TCR signaling pathway during alpha beta thymopoiesis. J Immunol 1999;163:3331-3343.

42 Barndt RJ, Dai M, Zhuang Y. Functions of E2A-HEB heterodimers in T-cell development revealed by a dominant negative mutation of HEB. Mol Cell Biol 2000;20:6677-6685.

43 Sawada S, Littman DR. A heterodimer of HEB and an E12related protein interacts with the CD4 enhancer and regulates its activity in T-cell lines. Mol Cell Biol 1993;13:5620-5628.

44 Sun XH. Constitutive expression of the Id1 gene impairs mouse B cell development. Cell 1994;79:893-900.

45 Kim D, Peng XC, Sun XH. Massive apoptosis of thymocytes in T-cell-deficient Id1 transgenic mice. Mol Cell Biol 1999;19:8240-8253.

46 Morrow MA, Mayer EW, Perez CA et al. Overexpression of the Helix-Loop-Helix protein Id2 blocks T cell development at multiple stages. Mol Immunol 1999;36:491-503.

47 Heemskerk MH, Blom B, Nolan G et al. Inhibition of T cell and promotion of natural killer cell development by the dominant negative helix loop helix factor Id3. J Exp Med 1997;186:15971602.

48 Blom B, Heemskerk MH, Verschuren MC et al. Disruption of alpha beta but not of gamma delta $\mathrm{T}$ cell development by overexpression of the helix-loop-helix protein Id3 in committed T cell progenitors. EMBO J 1999;18:2793-2802. 
49 Yokota Y, Mansouri A, Mori S et al. Development of peripheral lymphoid organs and natural killer cells depends on the helix-loop-helix inhibitor Id2. Nature 1999;397:702-706.

50 Rivera RR, Johns CP, Quan J et al. Thymocyte selection is regulated by the helix-loop-helix inhibitor protein, Id3. Immunity 2000;12:17-26.

51 Brown L, Cheng JT, Chen Q et al. Site-specific recombination of the tal-1 gene is a common occurrence in human T cell leukemia. EMBO J 1990;9:3343-3351.

52 Begley CG, Aplan PD, Denning SM et al. The gene SCL is expressed during early hematopoiesis and encodes a differentiation-related DNA-binding motif. Proc Natl Acad Sci USA 1989;86:10128-10132.

53 Fitzgerald TJ, Neale GA, Raimondi SC et al. c-tal, a helixloop-helix protein, is juxtaposed to the T-cell receptor-beta chain gene by a reciprocal chromosomal translocation: $\mathrm{t}(1 ; 7)(\mathrm{p} 32 ; \mathrm{q} 35)$. Blood 1991;78:2686-2695.

54 Xia Y, Brown L, Yang CY et al. TAL2, a helix-loop-helix gene activated by the $(7 ; 9)(\mathrm{q} 34 ; \mathrm{q} 32)$ translocation in human T-cell leukemia. Proc Natl Acad Sci USA 1991;88:11416-11420.

55 Mellentin JD, Smith SD, Cleary ML. lyl-1, a novel gene altered by chromosomal translocation in $\mathrm{T}$ cell leukemia, codes for a protein with a helix-loop-helix DNA binding motif. Cell 1989;58:77-83.

56 Wang J, Jani-Sait SN, Escalon EA et al. The t(14;21)(q11.2;q22) chromosomal translocation associated with T-cell acute lymphoblastic leukemia activates the BHLHB1 gene. Proc Natl Acad Sci USA 2000;97:3497-3502.

57. Wadman IA, Osada H, Grutz GG et al. The LIM-only protein Lmo2 is a bridging molecule assembling an erythroid, DNAbinding complex which includes the TAL1, E47, GATA-1 and Ldb1/NLI proteins. EMBO J 1997;161:3145-3157.

58 Chervinsky DS, Zhao XF, Lam DH et al. Disordered T-cell development and T-cell malignancies in SCL LMO1 doubletransgenic mice: parallels with E2A-deficient mice. Mol Cell Biol 1999;19:5025-5035.

59 Hsu HL, Wadman I, Baer R. Formation of in vivo complexes between the TAL1 and E2A polypeptides of leukemic T cells. Proc Natl Acad Sci USA 1994;91:3181-3185.

60 Park ST, Sun XH. The Tal1 oncoprotein inhibits E47-mediated transcription. Mechanism of inhibition. J Biol Chem 1998;273:7030-7037.

61 Herblot S, Steff AM, Hugo P et al. SCL and LMO1 alter thymocyte differentiation: inhibition of E2A-HEB function and pre-T alpha chain expression. Nature Immunol 2000;1:138.

62 Kadesch T. Helix-loop-helix proteins in the regulation of immunoglobulin gene transcription. Immunol Today 1992;13:31-36.

63 Schlissel M, Voronova A, Baltimore D. Helix-loop-helix transcription factor E47 activates germ-line immunoglobulin heavy-chain gene transcription and rearrangement in a pre-Tcell line. Genes Dev 1991;5:1367-1376.

64 Choi JK, Shen CP, Radomska HS et al. E47 activates the Ig-heavy chain and TdT loci in non-B cells. EMBO J 1996;15:5014-5021.
65 Sigvardsson M, O'Riordan M, Grosschedl R. EBF and E47 collaborate to induce expression of the endogenous immunoglobulin surrogate light chain genes. Immunity 1997;7:25-36.

66 Kee BL, Murre C. Induction of early B cell factor (EBF) and multiple B lineage genes by the basic helix-loop-helix transcription factor E12. J Exp Med 1998;188:699-713.

67 Leiden JM. Transcriptional regulation of $\mathrm{T}$ cell receptor genes. Annu Rev Immunol 1993;11:539-570.

68 Bain G, Romanow WJ, Albers K et al. Positive and negative regulation of $\mathrm{V}(\mathrm{D}) \mathrm{J}$ recombination by the E2A proteins. J Exp Med 1999;189:289-300.

69 Bernard M, Delabesse E, Smit L et al. Helix-loop-helix (E25, HEB, TAL1 and Id1) protein interaction with the TCRalphadelta enhancers. Int Immunol 1998;10:1539-1549.

70 Bain G, Murre C. The role of E-proteins in B- and T-lymphocyte development. Semin Immunol 1998;10:143-153.

71 Prabhu S, Ignatova A, Park ST et al. Regulation of the expression of cyclin-dependent kinase inhibitor $\mathrm{p} 21$ by E2A and Id proteins. Mol Cell Biol 11997;7:5888-5896.

72 Pagliuca A, Gallo P, De Luca P et al. Class A helix-loop-helix proteins are positive regulators of several cyclin-dependent kinase inhibitors' promoter activity and negatively affect cell growth. Cancer Res 2000;60:1376-1382.

73 Barone MV, Pepperkok R, Peverali FA et al. Id proteins control growth induction in mammalian cells. Proc Natl Acad Sci USA 1994;911:4985-4988.

74 Pui JC, Allman D, Xu L et al. Notch1 expression in early lymphopoiesis influences B versus T lineage determination. Immunity 1999;11:299-308.

75 Tomita K, Hattori M, Nakamura E et al. The bHLH gene Hes1 is essential for expansion of early $\mathrm{T}$ cell precursors. Genes Dev 1999;13:1203-1210.

76 Kaneta M, Osawa M, Sudo K et al. A role for pref-1 and HES1 in thymocyte development. J Immunol 2000;164:256-264.

77 Waterman ML, Jones KA. Purification of TCF-1 alpha, a Tcell-specific transcription factor that activates the T-cell receptor $\mathrm{C}$ alpha gene enhancer in a context-dependent manner. New Biol 1990;2:621-636.

78 Castrop J, van Wicker D, Koomans BM et al. The human TCF-1 gene encodes a nuclear DNA-binding protein uniquely expressed in normal and neoplastic T-lineage lymphocytes. Blood 1995;86:3050-3059.

79 van de Wetering M, Oosterwegel M, Dooijes D et al. Identification and cloning of TCF-1, a T lymphocyte-specific transcription factor containing a sequence-specific HMG box. EMBO J 1991;10:123-132.

80 Oosterwegel M, van de Wetering M, Timmerman J et al. Differential expression of the HMG box factors TCF-1 and LEF-1 during murine embryogenesis. Development 1993;118:439-448.

81 Oosterwegel M, van de Wetering M, Dooijes D et al. Cloning of murine TCF-1, a T cell-specific transcription factor interacting with functional motifs in the CD3-epsilon and $\mathrm{T}$ cell receptor alpha enhancers. J Exp Med 1991;173:1133-1142. 
82 Korinek V, Barker N, Moerer P et al. Depletion of epithelial stem cell compartments in the small intestine of mice lacking Tcf-4. Nat Genet 1998;19:379-383.

83 Verbeek S, Izon D, Hofhuis F et al. An HMG-box-containing T-cell factor required for thymocyte differentiation. Nature 1995;374:70-74

84 Schilham MW, Wilson A, Moerer P et al. Critical involvement of Tcf-1 in expansion of thymocytes. J Immunol 1998;161:3984-3991.

85 van Genderen C, Okamura RM, Farinas I et al. Development of several organs that require inductive epithelial-mesenchymal interactions is impaired in LEF-1-deficient mice. Genes Dev 1994;8:2691-2703.

86 Okamura RM, Sigvardsson M, Galceran J et al. Redundant regulation of $\mathrm{T}$ cell differentiation and TCRalpha gene expression by the transcription factors LEF-1 and TCF-1. Immunity 1998;8:11-20.

87 Galceran J, Farinas I, Depew MJ et al. Wnt $3 \mathrm{a}^{-1-}$ like phenotype and limb deficiency in Lef1 $\left({ }^{-1}\right) \operatorname{Tcf} 1\left(^{-{ }^{-}}\right)$mice. Genes Dev 1999;13:709-717.

88 Molenaar M, van de Wetering M, Oosterwegel M et al. XTcf-3 transcription factor mediates beta-catenin-induced axis formation in Xenopus embryos. Cell 1996;86:391-399.

89 Staal FJ, Burgering BM, van de Wetering M et al. Tcf-1-mediated transcription in T lymphocytes: differential role for glycogen synthase kinase- 3 in fibroblasts and T cells. Int Immunol 1999;11:317-323.

90 Cadigan KM, Nusse R. Wnt signaling: a common theme in animal development. Genes Dev 1997;11:3286-3305.

91 Clevers $\mathrm{H}$, van de Wetering M. TCF/LEF factors earn their wings. Trends Genet 1997;13:485-489.

92 Morin PJ, Sparks AB, Korinek V et al. Activation of $\beta$-cateninTcf signaling in colon cancer by mutations in $\beta$-catenin or APC. Science 1997;275:1787-1790.

93 Young CS, Kitamura M, Hardy S et al. Wnt-1 induces growth, cytosolic beta-catenin, and Tcf/Lef transcriptional activation in Rat-1 fibroblasts. Mol Cell Biol 1998;18:2474-2485.

94 Korinek V, Barker N, Willert K et al. Two members of the Tcf family implicated in Wnt/beta-catenin signaling during embryogenesis in the mouse. Mol Cell Biol 1998;18:1248-1256.

95 Itoh K, Krupnik VE, Sokol SY. Axis determination in Xenopus involves biochemical interactions of axin, glycogen synthase kinase 3 and beta-catenin. Curr Biol 1998;8:591-594.

96 Aberle H, Bauer A, Stappert J et al. Beta-catenin is a target for the ubiquitin-proteasome pathway. EMBO J 1997;16:3797-3804.

97 Farr GH, Ferkey DM, Yost C et al. Interaction among GSK3, GBP, axin, and APC in Xenopus axis specification. J Cell Biol 2000;148:691-702.

98 Roose J, Molenaar M, Peterson J et al. The Xenopus Wnt effector XTcf-3 interacts with Groucho-related transcriptional repressors. Nature 1998;395:608-612.
99 Peters JM, McKay RM, McKay JP et al. Casein kinase I transduces Wnt signals. Nature 1999;401:345-350.

100 Sakanaka C, Leong P, Xu et al. Casein kinase iepsilon in the wnt pathway: regulation of beta-catenin function. Proc Natl Acad Sci USA 1999;96:12548-12552.

101 Nusse R. WNT targets. Repression and activation. Trends Genet 1999;15:1-3.

102 Staal FJ, Meeldijk J, Moerer P et al. Wnt signaling is required for thymocyte development and activates Tcf-1 mediated transcription. Eur J Immunol 2001;31:285-293.

103 Austin TW, Solar GP, Ziegler FC et al. A role for the Wnt gene family in hematopoiesis: expansion of multilineage progenitor cells. Blood 1997;89:3624-3635.

104 Reya T, O'Riordan M, Okamura R et al. Wnt signaling regulates B lymphocyte proliferation through a LEF-1 dependent mechanism. Immunity 2000;13:15-24.

105 Schilham MW, Oosterwegel MA, Moerer P et al. Defects in cardiac outflow tract formation and pro-B-lymphocyte expansion in mice lacking Sox-4. Nature 1996;380:711-714.

106 Schilham MW, Moerer P, Cumano A et al. Sox-4 facilitates thymocyte differentiation. Eur J Immunol 1997;27:1292-1295.

107 Wharton KA, Johansen KM, Xu T et al. Nucleotide sequence from the neurogenic locus notch implies a gene product that shares homology with proteins containing EGF-like repeats. Cell 1985;43:567-581.

108 Milner LA, Bigas A. Notch as a mediator of cell fate determination in hematopoiesis: evidence and speculation. Blood 1999;93:2431-2448

109 Schroeter EH, Kisslinger JA, Kopan R. Notch-1 signalling requires ligand-induced proteolytic release of intracellular domain. Nature 1998;393:382-386.

110 Struhl G, Adachi A. Nuclear access and action of notch in vivo. Cell 1998;93:649-660.

111 Washburn T, Schweighoffer E, Gridley T et al. Notch activity influences the alphabeta versus gammadelta $\mathrm{T}$ cell lineage decision. Cell 1997;88:833-843.

112 Radtke F, Wilson A, Stark G et al. Deficient T cell fate specification in mice with an induced inactivation of Notch1. Immunity 1999;10:547-558.

$113 \mathrm{Kim}$ HK, Siu G. The notch pathway intermediate HES-1 silences CD4 gene expression. Mol Cell Biol 1998;18:7166-7175.

114 Ellisen LW, Bird J, West DC et al. TAN-1, the human homolog of the Drosophila notch gene, is broken by chromosomal translocations in T lymphoblastic neoplasms. Cell 1991;66:649-661.

115 Siu G, Wurster AL, Duncan DD et al. A transcriptional silencer controls the developmental expression of the $\mathrm{CD} 4$ gene. EMBO J 1994;13:3570-3579.

116 Sawada S, Scarborough JD, Killeen N et al. A lineage-specific transcriptional silencer regulates CD4 gene expression during T lymphocyte development. Cell 1994;77:917-929. 
117 Robey E, Chang D, Itano A et al. An activated form of Notch influences the choice between CD4 and CD8 T cell lineages. Cell 1996;87:483-492.

118 Gerondakis S, Grumont R, Rourke I et al. The regulation and roles of Rel/NF-kappa B transcription factors during lymphocyte activation. Curr Opin Immunol 1998;10:353-359.

119 Nolan GP. NF-AT-AP-1 and Rel-bZIP: hybrid vigor and binding under the influence. Cell 1994;77:795-798.

120 Burkly L, Hession C, Ogata L et al. Expression of relB is required for the development of thymic medulla and dendritic cells. Nature 1995;373:531-536.

121 Weih F, Carrasco D, Durham SK et al. Multiorgan inflammation and hematopoietic abnormalities in mice with a targeted disruption of RelB, a member of the NF-kappa B/Rel family. Cell 1995;80:331-340.

122 Arai K, Tsuruta L, Watanabe S et al. Cytokine signal networks and a new era in biomedical research. Mol Cells 1997;7:1-12.

123 Clipstone NA, Crabtree GR. Identification of calcineurin as a key signalling enzyme in T-lymphocyte activation. Nature 1992;357:695-697.

124 Hodge MR, Ranger AM, Charles de la Brousse F et al. Hyperproliferation and dysregulation of IL-4 expression in NF-ATpdeficient mice. Immunity 1996;4:397-405.
125 Ranger AM, Grusby MJ, Hodge MR et al. The transcription factor NF-ATc is essential for cardiac valve formation. Nature 1998;392:186-190.

126 Ranger AM, Hodge MR, Gravallese EM et al. Delayed lymphoid repopulation with defects in IL-4-driven responses produced by inactivation of NF-ATc. Immunity 1998;8:125-134.

127 Haus-Seuffert P, Meisterernst M. Mechanisms of transcriptional activation of cAMP-responsive element-binding protein CREB. Mol Cell Biochem 2000;212:5-9.

128 Shaywitz AJ, Greenberg ME. CREB: a stimulus-induced transcription factor activated by a diverse array of extracellular signals. Annu Rev Biochem 1999;68:821-861.

129 Rudolph D, Tafuri A, Gass P et al. Impaired fetal T cell development and perinatal lethality in mice lacking the cAMP response element binding protein. Proc Natl Acad Sci USA 1998;95:4481-4486.

130 Barton K, Muthusamy N, Chanyangam M et al. Defective thymocyte proliferation and IL-2 production in transgenic mice expressing a dominant-negative form of CREB. Nature 1996;379:81-85.

131 Outram SV, Varas A, Pepicelli CV et al. Hedgehog signaling regulates differentiation from double-negative to double-positive thymocytes. Immunity 2000;13:187-197. 
Transcriptional Control of T Lymphocyte Differentiation

Frank J.T. Staal, Floor Weerkamp, Anton W. Langerak, Rudi W. Hendriks and Hans C. Clevers

Stem Cells 2001;19;165-179

DOI: $10.1634 /$ stemcells.19-3-165

This information is current as of November 27, 2006

Updated Information

\& Services including high-resolution figures, can be found at:

http://www.StemCells.com/cgi/content/full/19/3/165

a AlphaMed Press 